\title{
Novos suportes, antigos temores: tecnologia e confronto de gerações nas práticas de leitura e escrita*
}

\author{
Solange Jobim e Souza
}

Pontifícia Universidade Católica do Rio de Janeiro, Departamento de Psicologia

Universidade do Estado do Rio de Janeiro, Faculdade de Educação

\section{Nilton Gamba Jr.}

Pontifícia Universidade Católica do Rio de Janeiro,

Programa de Pós-Graduação em Psicologia

Jamais houve uma época que não se sentisse moderna, no sentido excêntrico do termo, e não acreditasse estar diante de um abismo iminente. A lúcida consciência desesperada de estar no meio de uma crise decisiva é algo crônico na humanidade.

Walter Benjamin

\section{Introdução}

No idioma chinês, a palavra "crise" é construída a partir de dois ideogramas que significam "ameaça" e "oportunidade". Esta imagem está no cerne das questões que pretendemos abordar neste artigo. $\mathrm{O}$ trabalho de pesquisa que temos desenvolvido ao

* Trabalho apresentado em sessão especial realizada na $25^{\mathrm{a}}$ Reunião Anual da ANPEd (Caxambu, MG, 29 de setembro a 2 de outubro de 2002). longo destes quatro últimos anos ${ }^{1}$ contempla aspectos desta dupla provocação. Este tema tem nos levado a construir uma reflexão teórica para enfrentar o desafio de lidar com as transformações inerentes aos processos de produção de conhecimento na contemporaneidade. Nesta perspectiva, propomos a discussão das noções de novo e velho, passado e futuro, antigo e atual como categorias estanques, incentivando uma abordagem dialética destes conceitos, calcada na experiência prática, analisando juntamente com o leitor o modo como as mudanças são absorvidas pelas pessoas no seu dia-a-dia, especialmente no contexto da sala de aula.

\footnotetext{
${ }^{1}$ Estamos nos referindo ao trabalho de pesquisa do Grupo
} Interdisciplinar de Pesquisa da Subjetividade (GIPS), desenvolvido no âmbito do Departamento de Psicologia da PUC-Rio desde 1998, em que a pesquisa-intervenção é a modalidade principal que caracteriza nossas atividades de investigação e produção de conhecimento. Esta pesquisa é financiada pelo CNPq e pela FAPERJ. 
Nossa proposta não é apresentar resultados empíricos de pesquisa nesta área, mas propor uma reflexão que, tendo por base autores clássicos e contemporâneos de áreas disciplinares distintas, procure oferecer subsídios para o debate sobre o tema da tecnologia e confronto de gerações, propondo ações consistentes no âmbito educacional.

A questão da leitura e da escrita, por sua complexidade, poderia ser abordada privilegiando distintos recortes, porém nossa intenção é ressaltar dois aspectos em particular: a interferência do suporte ${ }^{2}$ que transforma os modos de leitura e de escrita através dos tempos; e a dificuldade de nos adaptarmos a estas mudanças na mesma velocidade que elas se apresentam a nós, exigindo habilidades que nem sempre estamos preparados para lidar de imediato.

\section{N ovas narrativas e produção de conhecimento: situando o tema na história}

O mundo atual caracteriza-se pela pluralidade das formas de compreender a realidade, exigindo o surgimento de novas narrativas no processo de produção de conhecimento. Este fato sugere a necessidade de reavaliarmos as condições atuais da produção do saber e os efeitos da diversidade de experiências sociopolítico-econômicas e das novas tecnologias nas práticas culturais de leitura e escrita. Dito isto, indagamo-nos: quais as condições sociais e culturais da leitura e da escrita nos dias de hoje? Como crianças, jovens e adultos lêem, o que lêem, como

2 O termo "suporte" é utilizado aqui como um conjunto de técnicas que define um veículo para transmissão de conteúdo. O livro, por exemplo, constitui-se como um suporte para escrita no qual o formato de códice com impressão em off-set que encontramos hoje é uma conseqüência da trajetória histórica de determinadas organizações produtivas e culturais que permitiram tecnologicamente e mercadologicamente esse formato atual. Assim como o livro, outros suportes se oferecem para a função de transmissão, e suas características técnicas e culturais acabam por fomentar o surgimento de novas linguagens e novos estilos de leitura e escrita. lêem? Estas questões estão diretamente relacionadas com as formas de produção do conhecimento na contemporaneidade, exigindo uma reflexão que explicite os condicionamentos que levam às transformações dos atos de ler e de escrever. Estes se apresentam como conseqüência de toda uma evolução, ao longo dos séculos, das forças produtivas. Isto significa dizer que as mudanças que vêm ocorrendo nos modos de produção de bens materiais no mundo globalizado refletem-se em todos os setores da cultura e da subjetividade. As transformações materiais, portanto, refletem-se na cultura e criam a base para o surgimento dos suportes que irão exigir novas práticas sociais de leitura e escrita e, conseqüentemente, o aparecimento de um novo leitor. Retomemos Walter Benjamin quando diz:

A escrita, que no livro impresso havia encontrado um asilo onde levava sua existência autônoma, é inexoravelmente arrastada para as ruas pelos reclames e submetida às brutais heteronomias do caos econômico. Essa é a rigorosa escola de sua nova forma. Se há séculos ela havia gradualmente começado a deitar-se, da inscrição ereta tornou-se manuscrito repousando oblíquo sobre a escrivaninha, para afinal acamar-se na impressão, ela começa agora, com a mesma lentidão, a erguer-se novamente do chão. Já o jornal é lido mais a prumo que na horizontal, filmes e reclames forçam a escrita a submeter-se de todo à ditatorial verticalidade. $\mathrm{E}$, antes que um contemporâneo chegue a abrir um livro, caiu sobre os seus olhos um tão denso turbilhão de letras cambiantes, coloridas, conflitantes, que as chances de sua penetração na arcaica quietude do livro se tornaram mínimas. Nuvens de gafanhotos de escritura, que hoje já obscurecem o céu do pretenso espírito para os habitantes das grandes cidades, se tornarão mais densas a cada ano seguinte. (1987, p. 28)

Escrito em 1930, o prognóstico de Benjamin é ainda atual. Cabe a nós, porém, continuar a encontrar respostas às novas indagações que o nosso tempo suscita. Estas novas modalidades de leitura estão nos formando, habilitando nossos órgãos perceptivos e intelectuais em novas direções, transformando nossa 
relação com o conhecimento. Se, por um lado, o livro exige concentração, um mergulhar atento e intencional nos signos impressos para extrair sentidos da narrativa textual, por outro, a leitura que fazemos das imagens-signos que circulam de forma intermitente requer dispersão. Ou seja, uma nova forma de lidar com a informação e o conhecimento já nos habita e entra em conflito com antigas formas de leitura. Que aprendizado podemos desenvolver a partir desta experiência?

Desde as primeiras formas de impressão, até as formas mais contemporâneas de leitura (cinema, televisão, vídeo, computador, impressos, outdoors etc.), percebemos como é cada vez mais difícil uma definição precisa e única de leitura e escrita. A velocidade da introdução desses novos meios na sociedade não é, muitas vezes, acompanhada por um movimento social e cultural de adaptação das pessoas às mudanças. As instituições que deveriam exercer esta função formativa são extremamente lentas, quando comparadas com a agilidade e a fugacidade das mudanças no campo social. Isto acarreta pessoas confusas em terminais bancários, a Internet subutilizada, dificuldades na programação dos aparelhos eletrônicos etc. Em contrapartida, percebemos que as novas gerações se inserem com maior facilidade nesta cultura modificada.

O turbilhão de estímulos visuais e sonoros que nos atravessa cotidianamente anuncia a necessidade de atualizarmos nossos conceitos sobre leitura escrita, incorporando a experiência com as novas imagenssignos. Devemos, portanto, refletir sobre o significado da aprendizagem e do conhecimento, considerando o momento da sociedade informacional e das redes que inserem, em tempo real, o local no global. Outras formas de lidar com a informação e o conhecimento vão se tornando parte de nossa experiência cotidiana, criando zonas de conflito entre jovens e adultos, que, inevitavelmente ao longo do processo histórico, representam grupos que se posicionam ante as tecnologias a partir de campos de visão totalmente distintos. Esta inadequação do homem à transmissão de sua experiência às gerações seguintes pode parecer um problema da atualidade. Entretanto, este equívoco logo se desfaz quando relacionamos as palavras de Walter Benjamin, anteriormente em destaque, com as palavras de Platão, que sublinhamos a seguir:

[...] quando chegou a vez da invenção da escrita, exclamou

Thoth: "Eis, oh Rei, uma arte que tornará os egípcios mais sábios e os ajudará a fortalecer a memória, pois com a escrita descobri o remédio para a memória".

Oh Thoth, mestre incomparável, uma coisa é inventar uma arte, outra é julgar os benefícios ou prejuízos que dela advirão para os outros! Tu, neste momento e como inventor da escrita, esperas dela, e com entusiasmo, todo o contrário do que ela pode vir a fazer! Ela tornará os homens mais esquecidos, pois que, sabendo escrever, deixarão de exercitar a memória, confiando apenas nas escrituras, e só se lembrarão de um assunto por força de motivos exteriores, por meio de sinais, e não dos assuntos em si mesmos. Por isso, não inventaste um remédio para a memória, mas sim para a rememoração. Quanto à transmissão do ensino, transmites aos teus alunos, não a sabedoria, pois passarão a receber uma grande soma de informações sem a respectiva educação! Hão de parecer homens de saber, embora não passem de ignorantes em muitas matérias e tornar-se-ão, por conseqüência, sábios imaginários, em vez de sábios verdadeiros. (Platão, 1994, p. 121)

Platão destaca o momento histórico em que a narrativa começa a ser gradualmente expulsa da esfera do discurso vivo, alertando para as conseqüências subjetivas de tal transformação mediada pelo advento da escrita. A presença do outro, mensageiro da palavra própria e da palavra alheia, não é mais necessária. Para Benjamin (1996), esta mudança se reflete na figura do narrador, aquele que se encontrava entre os mestres e os sábios, homem que sabia dar conselhos. Mas dar conselhos tornou-se antiquado na sociedade em que as informações são incontáveis e circulam velozmente. As experiências, ponto de encontro da vida e diálogo entre gerações, estão deixando de ser comunicáveis. Em conseqüência, diz Benjamin, não podemos dar conselhos nem a nós mesmos nem aos outros. A reminiscência é o fundamento da tradição, pois permite a transmissão dos acontecimentos de 
geração para geração, tecendo uma rede na qual todas as histórias se constituem entre si. Deste modo, para Benjamin, "aconselhar é menos responder a uma pergunta que fazer uma sugestão sobre a continuação de uma história que está sendo narrada. [...] O conselho tecido na substância viva da existência tem um nome: sabedoria" (1996, p.200).

O que está em discussão através das palavras de Walter Benjamin, e também em Platão, é que as transformações da narrativa no mundo contemporâneo não podem ser analisadas fora do contexto mais amplo das relações de produção da sociedade, a cada momento histórico. Se o narrador sabia contar histórias e mantinha uma relação artesanal entre a linguagem e a vida humana, hoje a informação é um jogo de linguagem que se assemelha à velocidade com que as coisas do mundo moderno são rapidamente substituídas, transformam-se em mercadoria, até mesmo as palavras que circulam entre as pessoas. A informação, desvinculada do diálogo vivo, pode conduzir-nos, como diz Platão, a uma aparência de sabedoria, tornando-nos sábios imaginários, e não verdadeiros sábios. E Benjamin, continuando esta reflexão, acrescenta: "A arte de narrar está definhando porque a sabedoria - o lado épico da verdade - está em extinção” (1996, p. 200-201).

O diálogo entre Platão e Walter Benjamin, o primeiro remetendo-se a invenção da escrita, o segundo refletindo sobre o declínio da arte de narrar, aponta para uma mesma questão: a identificação da linguagem como instrumento técnico na época moderna. Ao nos determos sobre as questões trazidas por estes autores, podemos nelas enxergar um comportamento crítico que deve alimentar permanentemente o enfrentamento com o novo, porém sem transformá-lo em preconceito ou rejeição ante os desafios de cada época. Faz-se necessário, portanto, a construção de posturas mais adequadas aos processos de criação e produção de conhecimento mediados pelos instrumentos técnicos criados pelo homem no processo histórico. Encontramos, assim, um duplo vetor de difícil conciliação, mas que exige um esforço inadiável de todos que compartilham a experiência contemporânea: a ca- pacidade de desenvolver parâmetros críticos para lidar com a novidade, ao mesmo tempo em que alimentamos um verdadeiro despojamento dos preconceitos e dos entraves que nos impedem de apreender a linguagem de fato. O novo deve, assim, ser incorporado como experiência simultânea de sociabilidade e transformação da subjetividade.

Mais recentemente, estas mesmas questões foram retomadas por Pierre Levy (1995), que apresenta, de modo mais sistemático, ou didático, os diferentes momentos de transformação do homem na sua relação com a linguagem. O seu propósito, porém, é discutir os efeitos das tecnologias da inteligência nos modos de conhecimento e subjetivação na contemporaneidade. $\mathrm{O}$ autor estuda a linguagem dividindo-a em dois tempos. No primeiro tempo, denominado tempo da oralidade primária, linguagem e memória eram dois aspectos de um mesmo fenômeno. A organização temporal da narrativa desenhava o tempo como circular. As histórias eram contadas de boca em boca, preservando uma estreita relação entre a vida, a linguagem e a memória. O tempo repetia-se na linguagem, no contar sempre de novo as histórias. A idéia que não fosse retomada e repetida em voz alta estava condenada ao desaparecimento. $\mathrm{O}$ conhecimento, então, constituía-se na reiteração da narrativa oral e a linguagem revelava a experiência circular com o tempo. Todo o acervo cultural do homem estava na manutenção do círculo progressivo das lembranças. A invenção da escrita vai, contudo, interromper a cadeia da circularidade das narrativas orais. O segundo tempo, tempo da escrita, vai interferir de forma decisiva no modo de conhecer. Ao escrever a sua história, o homem rompe com a circularidade temporal e inaugura uma nova experiência com a temporalidade: $o$ tempo cronológico e linear. Neste momento, operase uma transformação fundamental, pois o conhecimento começa a ser separado do sujeito que o produz e um novo problema é colocado: a questão da verdade, principal preocupação da ciência moderna. Enquanto os homens contavam uns para os outros as suas histórias, o sentido ia sendo construído no diálogo. A presença do falante e do ouvinte garantia a compreen- 
são e o controle da verdade. Retomando Platão uma vez mais, no diálogo entre Sócrates e Fedro esta questão se apresenta da seguinte maneira:

\begin{abstract}
SOCRÁTES - O maior inconveniente da escrita parece-se, caro Fedro, se bem julgo, com a pintura. As figuras têm atitudes de seres vivos mas, se alguém as interroga, manter-se-ão silenciosas, o mesmo acontecendo com os discursos: falam das coisas como se estas estivessem vivas, mas, se alguém os interroga, no intuito de obter um esclarecimento, limitam-se a repetir sempre a mesma coisa. Mais: uma vez escrito, um discurso chega a toda parte, tanto aos que o entendem como aos que não podem compreendê-lo e, assim, nunca se chega a saber a quem serve e a quem não serve. Quando é menoscabado, ou justamente censurado, tem sempre necessidade da ajuda do seu autor, pois não é capaz de se defender nem de se proteger a si mesmo. (Platão, 1994, p. 122-123)
\end{abstract}

A escrita vai, portanto, marcar uma primeira e grande cisão do homem não só com a sua memória, mas também com os modos anteriores de gerar conhecimento. A memória natural vai sendo substituída pela memória artificial. Quanto mais o mundo avança e torna-se complexo e sofisticado, mais o homem necessita de novas tecnologias para dar conta do enorme turbilhão de informações que circulam velozmente entre nós. Hoje vivemos o terceiro tempo, tempo da informática, da telemática, ou seja, tempo da mais absoluta digitalização e condensação da experiência humana em chips, imagens, impulsos eletrônicos etc. A objetificação da memória automatiza-se a tal ponto que nos indagamos se a noção que temos de memória é ainda pertinente. A tecnologia nos conduz a novas indagações e a uma nova consciência dos movimentos da memória, materializando uma experiência que imita a mente humana no seu modo de associação simultânea de idéias. O pensamento pode ser representado como um texto que se ramifica, construindo, na confluência de diferentes vozes e imagens, um equilíbrio entre o espaço, o tempo e o sujeito. Torna-se possível intervir no fluxo da narrativa, permitindo que a simultaneidade e a transversalidade da experiência subjetiva sejam representáveis no espaço e no tempo. A técnica permite ampliar, para fora do sujeito, o próprio processo de cognição, produção e transmissão de conhecimentos. Cada vez mais o conhecimento se equipara a processos híbridos, compondo uma rede que liga lembranças, acontecimentos, textos, imagens, objetos etc. O pensamento, com ajuda da tecnologia, revela-se como um imenso hipertexto. Com a tecnologia conquista-se uma consciência mais profunda do modo de funcionamento do pensamento humano, o que acaba por transformar o próprio pensamento em produto da cultura.

Benjamin (1996) afirma: "Nunca houve um monumento de cultura que não fosse também um monumento de barbárie. E, assim como a cultura não é isenta de barbárie, não o é, tampouco, o processo de transmissão da cultura" (p.225). Esta frase exige reflexão e tomada de consciência dos efeitos que a tecnologia traz para a experiência humana. Embora seja evidente toda a positividade da tecnologia para o progresso da humanidade, a atitude crítica é indispensável para não sermos contagiados pela euforia ingênua que tomou conta da humanidade na época moderna.

A linguagem, quando vinculada a uma novidade tecnológica, coloca o homem em uma situação de fascínio e risco, ou melhor, evidencia uma questão de ordem filosófica que exige uma postura crítica, mas também prática. Esta última traduz-se no modo como atualizamos e re-afirmamos nossa condição de autores deste processo e não perdemos a capacidade de encontrar respostas compartilhadas entre as gerações para os novos desafios.

\section{Tecnologia e confronto de gerações}

Martín-Barbero (2000) retoma uma importante contribuição de Margaret Mead ${ }^{3}$, quando a autora, ainda na década de 1970, destacou a necessidade de construir-se uma compreensão crítica sobre a questão da

\footnotetext{
3 M. Mead, Cultura y compromisso, Barcelona, Gránica,
} 1971. 
ruptura entre gerações na grande temporalidade. Mead chamou a atenção para a necessidade de enfrentarmos nossos medos em relação às mudanças, reconhecendo neste desafio as possibilidades que se abrem para novos diálogos entre gerações e povos para alcançarmos uma compreensão histórica e cultural da nossa inserção como sujeitos sociais no contexto da revolução eletrônica.

Nascida antes da revolução eletrônica, a maioria de nós não entende o que esta significa. Os mais jovens da nova geração em mudança se assemelham aos membros da primeira geração nascida em um país novo. Devemos aprender com os jovens a forma de dar os primeiros passos. Porém, para proceder assim, devemos relocalizar o futuro. Ao juízo dos ocidentais, o futuro está diante de nós. Ao juízo de muitos povos da Oceania, o futuro reside atrás, não adiante. Para construir uma cultura na qual o passado seja útil, não coativo, devemos localizar o futuro entre nós como algo que está aqui pronto para que o ajudemos e o protejamos antes que nasça, porque, do contrário, será demasiado tarde. (Mead apud Martín-Barbero, 2000, p. 105)

Em sala de aula, na relação com a leitura e a escrita, encontramos hoje a representação concreta desse abismo entre gerações. De um lado, o professor, com sua história e sua temporalidade inscritas em modos particulares de leitura, formados com base em sua inserção acadêmica e profissional; de outro lado, o aluno, representando o novo trazido por sua geração e pela cultura já modificada que a permeia. Nesse distanciamento espaço-temporal entre a história do professor e a vivência do aluno é que percebemos nos artefatos culturais, ou seja, nos objetos concretos que passam a mediar as relações de alunos e professores com os atos de leitura e escrita, um obstáculo que por vezes dificulta a integração da experiência de adultos e crianças.

Pier Paolo Pasolini (1990), no texto "Genariello: a linguagem pedagógica das coisas", nos apresenta com lucidez e eloqüência o abismo que separa as gerações através da ausência de um sentido compartilhado para se compreender os objetos culturais que permeiam as relações entre as pessoas de uma dada época.
Minha cultura (com seus esteticismos) me coloca numa postura crítica em relação às "coisas" modernas entendidas como signos lingüísticos. A tua cultura, ao contrário, te faz aceitar essas coisas modernas como naturais e acolher o seu ensinamento como absoluto.

Não vou jamais me cansar de repetir: eu, quando falo com você, posso até ter a força de esquecer, ou de querer esquecer, o que me foi ensinado com as palavras. Mas não posso jamais esquecer o que me foi ensinado com as coisas. Portanto, no âmbito da linguagem das coisas é um verdadeiro abismo que nos separa: ou seja, um dos mais profundos saltos de geração que a história possa recordar. Aquilo que as coisas com sua linguagem me ensinaram é absolutamente diferente daquilo que as coisas com sua linguagem ensinaram a você. Não mudou, porém, a linguagem das coisas, caro Genariello: são as próprias coisas que mudaram. E mudaram de maneira radical.

E é um fim de mundo o que aconteceu entre mim, que tenho cinquienta anos, e você, que tem quinze. Minha figura de pedagogo é então irremediavelmente colocada em crise. Não se pode ensinar se ao mesmo tempo não se aprende. (p.131-132)

Podemos aproveitar as reflexões de Pasolini e Mead para discutir os impasses que se apresentam no contexto das relações entre professor e aluno. Na medida em que sabemos que o suporte da escrita é agente modificador da mesma, e sabendo também que o suporte é permanentemente atualizado pelos avanços da tecnologia, é imprescindível admitirmos a distância entre a experiência do professor e a do aluno quanto aos suportes, e, portanto, quanto aos seus modos de escrita. A Internet, os games, os sistemas computacionais interativos geram uma diversidade de suportes para a leitura e a escrita que se apresentam de formas diversas para esses dois personagens - o professor e o aluno - exemplificando, no âmbito educacional, a discussão que estes autores estavam a sugerir, na década de 1970, para compreendermos melhor a mutação radical trazida pelos avanços tecnológicos e as conseqüências destes avanços para o diálogo entre as gerações. Vale ressaltar que a reflexão sobre o abismo entre gerações deve ser realizada 
em conjunto com uma outra questão igualmente importante, ou seja, a do abismo gerado entre culturas, povos e classes sociais com acessos desiguais aos bens materiais que circulam entre nós no contexto de uma época determinada.

Levando em consideração as questões aqui apresentadas, podemos afirmar que a revolução tecnológica nos coloca um desafio fundamental, qual seja, o de compreendermos que estamos diante do surgimento de uma outra cultura, que exige de nós uma adaptação nos modos de ver, de ler, de pensar e de aprender. Entretanto, vale uma ressalva, pois mesmo que o turbilhão de imagens que nos atravessa cotidianamente anuncie a necessidade de construirmos novos conceitos sobre leitura e escrita que incorporem a experiência com imagens-signos, ainda assim, nós, como educadores, devemos admitir que o livro continua tendo um lugar fundamental nesta rede híbrida e incentivar uma reflexão sobre o seu papel no contexto atual. $\mathrm{Na}$ verdade, o livro afirma-se como um dos elos neste imenso hipertexto que atualiza a nossa relação com a cultura. $\mathrm{O}$ hipertexto é o exemplo mais marcante e atual da transformação do ato de leitura como recriação dos movimentos do pensamento, ou melhor, da subjetividade do leitor; mas o hipertexto também configura a experiência do sujeito com a realidade externa, impregnada por uma multiplicidade de imagenssignos. A cada instante surgem novas narrativas para serem decifradas e interpretadas pelos sujeitos que nascem e se criam na civilização da imagem. Para continuar esta discussão, duas questões fundamentais são colocadas: é possível uma concepção de leitura que implique o sujeito nos seus aspectos tanto emocionais como racionais, não importando o momento histórico em que o sujeito leitor se encontre situado? Ou melhor, como falar de leitura implicando, ao mesmo tempo, os instrumentos e suas especificidades, redimensionando a cultura do sujeito leitor sem excluir o sujeito histórico?

Ora, o verdadeiro ato de ler não perde o seu entrelaçamento original com a oralidade primária, aquela fase da experiência humana em que, segundo Levy (1995), linguagem e memória eram elementos indis- sociáveis e complementares. A leitura implica sociabilidade, ou melhor, a leitura só se realiza plenamente quando o leitor sabe compartilhar com outras pessoas, presentes ou ausentes, significações. Benjamin (1996) apresenta a figura do narrador como aquele que pode recorrer ao acervo de toda uma vida, uma vida que não inclui apenas a própria experiência, mas em grande parte a experiência alheia, assimilando à sua substância mais íntima aquilo que sabe por ouvir dizer:

A narrativa, que durante tanto tempo floresceu num meio de artesãos - no campo, no mar e na cidade -, é ela própria, num certo sentido, uma forma artesanal de comunicação. Ela não está interessada em transmitir o "puro em si" da coisa narrada como uma informação ou um relatório. Ela mergulha a coisa na vida do narrador para em seguida retirá-la dele. Assim se imprime na narrativa a marca do narrador, como a mão do oleiro na argila do vaso. (p. 205)

A leitura não é um ato solitário, mas o encontro com as muitas vozes que ecoam no texto de um escritor e que só terão oportunidade de se manifestar pelo encontro marcado entre o leitor e o texto. A leitura é comunhão, é o momento em que o indivíduo isolado se vê perante a possibilidade de reconhecer a sua inserção particular na história de uma época. Com base na narrativa de outrem, a minha própria identidade se restabelece. Ler é um modo de viajar e deixar-se impregnar pela névoa do desconhecido. O desafio maior que enfrentamos hoje é preservar a dimensão mágica da leitura no contexto da utilização da tecnologia. Entretanto, este novo modo de leitura instrumental precisa partilhar com a leitura mágica a possibilidade de submeter-se ao tempo do leitor. O tempo do leitor é a garantia da atividade crítica, dando uma nova permanência histórica e cultural às narrativas que se constituem e se renovam na grande temporalidade.

Reivindicar a presença da cultura oral, da cultura letrada e da cultura audiovisual no espaço escolar é incentivar o diálogo profícuo entre os variados modos de construção do saber que circulam entre nós, seja em diferentes espaços sociais ou em um mesmo contexto espaço-temporal. O livro, em vez de segre- 
gar ou de se fechar em si mesmo, deve se integrar neste novo processo de aprendizagem, abrindo espaço para a realização das múltiplas escrituras. A transformação nos modos como circula o saber é, portanto, a questão fundamental na atualidade, exigindo das gerações precedentes um esforço para incorporar novos hábitos de produção de conhecimento que escapam dos lugares sagrados - o livro e a escola - que antes continham e legitimavam o saber.

Além disto, hoje constatamos que as figuras do professor e da família estão se enfraquecendo como autoridades que detinham o poder de administrar a educação aos jovens, uma vez que o acesso à informação se diversifica radicalmente por intermédio dos meios de comunicação. Diante desta ameaça de desmoronamento de sua autoridade ante o aluno, o professor reage, muitas vezes, desautorizando os saberes que passam pela imagem e que reivindicam a presença de novas habilidades sensoriais e cognitivas. Assim sendo, o professor nem sempre se dá conta de que estamos diante de uma transformação dos processos de leitura, de escrita e de produção de conhecimento que apontam para um redimensionamento da cultura e da subjetividade, um desafio para todos que enfrentam e compartilham este momento histórico. Não se trata, portanto, de usar a tecnologia apenas como modo de expandir as antigas formas de ensinoaprendizagem, ou ter a mídia na escola como meio para amenizar o tédio do ensino, mas trata-se de um modo radicalmente novo de inserção da educação nos complexos processos de comunicação da sociedade atual (Martín-Barbero, 2000; Martín-Barbero \& Rey, 2001).

Com isso queremos dizer que a escola precisa enfrentar e questionar a profunda reorganização que vive o mundo das linguagens e das escritas, reformulando a obstinada identificação da leitura com o que se refere somente ao livro. Hoje é imprescindível levarmos em conta a pluralidade e a heterogeneidade de textos, relatos e escrituras (orais, visuais, musicais, audiovisuais, telemáticos) que circulam entre nós. Esta atitude tem implicações políticas graves, na medida em que a exclusão social na contemporaneidade passa, necessariamente, pelo acesso das popu- lações marginalizadas aos novos modos de obter e gerar conhecimento. Na medida em que as crianças mais abastadas entram em contato com as mediações tecnológicas no contexto da família, a escola constitui-se, em nossa realidade social, especialmente para as crianças pobres, o espaço privilegiado de acesso às novas formas de conhecimento que a tecnologia prefigura.

\section{Alteridade, tempo e espaço: elementos para uma análise das relações entre as gerações}

Para discutir o tema da tecnologia e o confronto de gerações, trazemos agora outro autor, Mikhail Bakhtin (1985), por meio de três conceitos fundamentais, para analisarmos o confronto de gerações nas práticas de leitura e escrita: cronotopia, alteridade e gêneros discursivos. Orientando-se pela física, cujas leis se baseiam nas noções de espaço e tempo, Bakhtin desenvolveu uma abordagem semiótica, garantindo às relações dialógicas um modo de representação de diferentes visões de mundo cronotopicamente configuradas, mostrando que cada enunciado se encontra em um ponto único e em confronto interativo com outros possíveis enunciados, situados em pontos únicos diversos.

Bakhtin (1985) afirma que todas as visões são determinadas pelo posicionamento do sujeito no espaço e no tempo. Um indivíduo sempre vê o que está fora do campo de visão de um outro. Isso significa dizer que no campo de visão de um sujeito há sempre algo que não é possível ser alcançado por sua visão, devido à sua localização no espaço. Este espaço não preenchido pela visão do sujeito é o excedente de visão que só pode ser preenchido pela posição de um outro sujeito no espaço. Portanto, aquilo que é inacessível ao olhar de uma pessoa é preenchido pelo olhar de outra pessoa. Ao campo espacial adicionamos a perspectiva temporal, pois cada sujeito histórico habita uma determinada experiência temporal que também irá marcar profundamente o modo como percebe o presente, o passado e o futuro. Deste modo, Bakhtin sugere que cada um de nós prescinde e ne- 
cessita irremediavelmente do outro, e que esta condição essencialmente alteritária do outro em relação a mim é fundamental para a experiência humana na sua plenitude, encaminhando uma compreensão cada vez mais aperfeiçoada da nossa cultura e de nós mesmos.

Nesta perspectiva de análise, a distância espaçotemporal entre as gerações, em vez de se tornar um obstáculo para se compreender melhor a nossa época, passa a ser uma solução promissora, posto que a dimensão alteritária entre as visões do adulto, da criança e do jovem sobre um mesmo objeto, enriquece definitivamente nossas possibilidades de compreensão do objeto em questão como um artefato da cultura. Em se tratando da escrita como um objeto cultural e da leitura como uma prática social, como equacionar os conceitos de Bakhtin para se compreender a produção de textos nos ambientes da tecnologia eletrônico-digital?

Aprendemos com Bakhtin que a magnitude cultural de uma época, a riqueza de suas criações, não cabem nos limites da visão que lhes é contemporânea, mas exigem o confronto transtemporal que é revelador da época e de suas grandezas. $\mathrm{O}$ autor afirma que "não existe nada morto de forma absoluta: cada sentido terá sua festa de ressurreição. Problema da grande temporalidade" (1985, p. 352). Encontramos um diálogo muito próximo entre as palavras de Pasolini e Mead, sobre os acontecimentos do cotidiano entre as gerações, e a abordagem teórica de Bakhtin, que nos oferece os conceitos adequados para uma análise do acontecimento cotidiano como uma experiência de linguagem e de criação cultural que atravessa gerações. É com esta perspectiva de análise que enfrentamos o desafio que foi proposto anteriormente, qual seja: a capacidade de desenvolver parâmetros críticos para lidar com a novidade, ao mesmo tempo em que alimentamos um verdadeiro despojamento dos preconceitos e dos entraves que nos impedem de apreendê-la de fato.

Para caminharmos nesta direção, uma primeira compreensão impõe-se: a de percebemos as escrituras contemporâneas e seus respectivos suportes como gê neros discursivos que traduzem formas específicas do uso da língua e da criação de textos numa dada época. Bakhtin não admite hierarquia nos gêneros discursivos, mas enfatiza esta característica da linguagem como um fenômeno que revela pluralidade, jamais uma abordagem forjada em classificações. O próprio termo texto aproxima-nos de uma compreensão da linguagem como tessitura, combinação, enredamento, modos de tecer redes de relações cujo resultado é o sentido provocado pelo texto nos seus interlocutores. O texto diz respeito a toda uma produção cultural fundada na linguagem. No conjunto das idéias de Bakhtin, a noção de textualidade está de tal forma vinculada ao enunciado que em nenhum momento é possível cogitar sobre a existência de campo de oposição ou polaridade entre os gêneros da oralidade e da escritura. A fala não se opõe à escrita, ao contrário, a diversidade e a inter-relação dos gêneros discursivos tornam muito mais complexa tanto a textualidade oral quanto a escrita. Podemos também afirmar que as diversas escrituras que transitam entre palavras, imagens e imagenssignos não se opõem entre si, mas se completam e se complementam como tentativas de expressar os acontecimentos da vida cotidiana, ou melhor, a linguagem em ação que se evidencia na vida prática.

$O$ conceito de gênero discursivo, tal como apresentado por Bakhtin, ajuda-nos a compreender e lidar com as novas textualidades mediadas por suportes eletrônicos e digitais, presentes em nossas manifestações culturais. No mundo das comunicações interativas da vida cotidiana, mundo em permanente devir, os gêneros discursivos vão adquirindo um contorno mais preciso. Vale ressaltar, entretanto, que em nenhum momento as diferentes visões de mundo refletidas ou refratadas nos gêneros discursivos se anulam, mas coexistem, criando novas possibilidades de sentidos adequados ao tempo presente. Assim, os gêneros discursivos criam verdadeiras cadeias de sentidos que se renovam na grande temporalidade, consubstanciando visões de mundo que acompanham a variabilidade de usos da língua num determinado tempo e espaço. A vinculação estreita entre gênero discursivo e suas transformações no tempo e no espaço faz com que o gênero do discurso não possa ser sequer pensado fora 
de sua dimensão cronotópica. Assim sendo, podemos compreender a escrita e suas transformações históricas como um gênero discursivo que se constitui pela expansão e pelo redimensionamento dos suportes na cultura. De fato, a experiência com a variedade de suportes enriquece o processo de criação e deixa espaço para a renovação da cultura e da própria experiência subjetiva. Vivemos sob a égide da combinação, e nenhum produto cultural do universo semiótico deve ser considerado isoladamente. A oralidade, a escrita impressa e a escrita eletrônica não são momentos distintos de um processo em evolução, mas devem ser apreciados com base na conjugabilidade e na sociabilidade de um mesmo momento histórico e preciso. Na medida em que o professor e o aluno compartilham os desejos de ensinar e de aprender como situações que podem ser intercambiadas entre ambos, e que a leitura e a escrita passam a ser atividades que se constituem no campo social, e não como aprendizagens meramente técnicas e funcionais, a relação entre gerações atinge uma outra configuração, abrindo perspectivas promissoras ante os desafios postos pela tecnologia. Martín-Barbero (2000) sustenta nossa reflexão por meio do seguinte relato:

Estamos diante de uma geração que mais que na escola é na televisão, captada por antena parabólica, onde tem aprendido a falar inglês, que experimenta uma forte empatia com o idioma das novas tecnologias e que crescentemente gosta mais de escrever no computador do que no papel. Empatia que se apóia numa plasticidade neuronal (Piscitelli, 1994) que dota os adolescentes de uma enorme capacidade de absorção de informação, seja via televisão ou em videogames, e de uma quase natural facilidade de entrar e manipular a complexidade das redes informáticas.

Frente à distância com que grande parte dos adultos sente e resiste a essa nova cultura - que desvaloriza e torna obsoletos muitos de seus saberes e habilidades -, os jovens respondem com uma intimidade feita não só da facilidade para relacionar-se com as tecnologias audiovisuais e informáticas, mas da cumplicidade cognitiva e expressiva: é nos relatos e imagens, nas suas sonoridades, fragmentações e velocidades que encontram seu ritmo, seu idioma. (p. 86)
A produção do conhecimento hoje não dispensa a nossa capacidade de dialogar com os aparatos tecnológicos, incentivando as pessoas a construírem, com eles, novas possibilidades de usos, submetendo as máquinas ao nosso poder e desejo de inventar outros jogos ainda não revelados na prática. Trata-se, portanto, de criarmos, por meio da educação, modos de confronto com a experiência tecnológica, colocando tanto educadores como educandos na posição de se sentirem responsáveis por inventar outras estratégias de interação na produção de conhecimento. Isto significa dizer que a educação mediada pela tecnologia é um jogo, pois cada vez mais as máquinas se transformam em aparatos para recuperarmos a dimensão lúdica na produção do conhecimento, que é de fato também trabalho. A relação entre jogo e trabalho, no contexto da tecnologia, transforma-se de modo radical. Como diz Flusser (1998), "os instrumentos técnicos emancipam o homem do trabalho, libertando-o para o jogo".

$\mathrm{O}$ adulto precisa aprender com o jovem que a tecnologia pode ser vivida como uma experiência lúdica, os aparelhos podem ser brinquedos, e jogar contra o aparelho é um modo de resgatar a liberdade num mundo programado pela tecnologia (Flusser, 1998). Em contrapartida, tanto a criança quanto o jovem precisam aprender com o adulto a história em evolução e que a cultura precedente é o fundamento da experiência atual. É necessário rompermos com as barreiras intransponíveis entre as gerações que acabam por isolar os jovens da cultura dos mais velhos, impedindo-os de manter com seus pais e professores uma relação dialética. De acordo com Pasolini (1990), só através de tal relação dialética, ainda que dramática e exacerbada, é que os filhos podem tomar uma real consciência histórica de si mesmos, seguir adiante e "superar" os pais. Em contrapartida, o isolamento no qual os jovens e os adultos se fecham os mantém resistentes à sua própria e inescapável realidade histórica. Isso implica fatalmente retrocesso. Nem a palavra isolada do adulto, nem a palavra isolada do jovem, mas o diálogo como solução para a continuidade do presente no futuro. Um futuro carregado de histórias que merecem ser, uma vez mais, contadas. 
SOLANGE JOBIM E SOUZA, psicóloga e doutora em educação, é professora do Departamento de Psicologia da PUC-Rio e da Faculdade de Educação da UERJ. Pesquisadora do CNPq e da FAPERJ, coordena o Grupo Interdisciplinar de Pesquisa da Subjetividade (GIPS), que integra as atividades do Programa de PósGraduação do Departamento de Psicologia da PUC-Rio. Assessora da MULTIRIO - Empresa Municipal de Multimeios Ltda. Publicou: Leitura entre o mágico e o profano. Os caminhos cruzados de Bakhtin, Benjamin e Calvino (In: FARACO, C. A. et al. Diálogos com Bakhtin. Curitiba: Editora da UFPR, 1996) e Imagens do conhecimento (Rio de Janeiro: Rios Ambiciosos e FAPERJ, 2000). E-mail: soljobim@uol.com.br

NILTON GAMBA JÚNIOR, mestre em artes, é doutorando do Programa de Pós-graduação em Psicologia Clínica da PUCRio. Membro do Grupo Interdisciplinar de Pesquisa da Subjetividade. E-mail: gambajr@openlink.com.br

\section{Referências bibliográficas}

BAKHTIN, M., (1985). Estética de la creación verbal. Madrid: Siglo Veintiuno.

BENJAMIN, Walter, (1996). O narrador; considerações sobre a obra de Nikolai Leskov. In: Obras escolhidas. Magia e técnica, arte e política, $1^{\mathrm{a}}$ reimp. São Paulo: Brasiliense. v. I.
, (1987). Walter Benjamin - Obras escolhidas. Rua de Mão Única. São Paulo: Brasiliense. v. II.

FLUSSER, V., (1998). Ensaio sobre a fotografia. Para uma filosofia da técnica. Lisboa: Relógio d’Água.

LEVY, Pierre, (1995). As tecnologias da inteligência; o futuro do pensamento na era da informática. Rio de Janeiro: Editora 34.

MARTÍN-BARBERO, J., (2000). Novos regimes de visualidade e descentramentos culturais. In: VALTER, F., (org.). Batuques, fragmentações e fluxos. Rio de Janeiro: DP\&A.

MARTÍN-BARBERO, J., REY, Germán, (2001). Os exercícios do ver; hegemonia audiovisual e ficção televisiva. São Paulo: Ed. Senac.

PASOLINI, P. P., (1990). Os jovens infelizes. São Paulo: Brasiliense.

PISCITELLI, A., (1994). Del péndulo a la maquina virtual. In: BLEICMAR, S., (comp.). Temporalidad, determinación, azar. Buenos Aires: Paidós.

PLATÃO, (1994). Fedro ou da Beleza. $5^{\mathrm{a}}$ ed. Lisboa: Guimarães Editores. 
between the civilisation process and the monopolisation of the elementary school by the State.

Key-words: schooling, civilisation, state.

Cynthia Greive Veiga

Novos suportes, antigos temores: tecnologia e confronto de gerações nas práticas de leitura e escrita

Analisa as condições de produção de conhecimento na contemporaneidade e os condicionamentos sociais, políticos e culturais que levam às transformações do ato de ler e de escrever. A questão da leitura e da escrita é tratada sob dois aspectos: a interferência de suportes, que transforma os modos de leitura e da escrita através dos tempos; e os desafios trazidos pela revolução eletrônica para o diálogo entre as gerações. Conceitos desenvolvidos por Mikhail Bakhtin são retomados neste contexto para elaborar uma compreensão dos atuais usos da linguagem e criação de textos mediados por suportes eletrônicos e digitais.

Palavras-chave: tecnologia, práticas de leitura e escrita.

New supporting materials, old fears: the technology and the generation clashes in the reading and writing practices

The paper analyses contemporary production of knowledge about the act of reading and writing, as well as the social, political and cultural conditionings that have led to changes in it. We focus on two aspects related to the issue: the impact of the supporting materials that have changed ways of reading and writing throughout time; and the challenges imposed on the dialogue between generations, brought about by the electronic revolution. We revisit concepts developed by Mikhail Bakhtin, casting new lights upon the present uses of language and text production mediated by electronic and digital supporting materials.
Key-words: technology, reading and writing practices, supporting materials.

Maria de Lourdes de Albuquerque Fávero

\section{GT Política de Educação Superior} da ANPEd: origem, desenvolvimento e produção

O estudo objetiva oferecer subsídios para a compreensão da trajetória do GT Política de Educação Superior, situando suas origens, sua construção e desenvolvimento. Na história desse GT, destaca como os seminários de intercâmbio e, em especial, o projeto integrado de pesquisa "Produção científica sobre educação superior no Brasil: 1968-2000" contribuíram para seu caminhar, proporcionando avanços na reflexão coletiva sobre seu papel e questões de política de educação superior a ele afetas, bem como fortalecendo sua produção. Em uma visão prospectiva e tendo presente que o trabalho de consolidação de um grupo como este é empreendimento que resulta de um processo de construção permanente, indica questões a serem discutidas e aprofundadas pelos seus membros.

Palavras-chave: GT Política de Educação Superior.

Origins, development and production of the ANPEd Working Group on Higher Education Policy This study seeks to offer subsidies for understanding the trajectory of the Working Group on Higher Education Policy, situating its origins, construction and development. In the history of this working group, emphasis is given as to how the seminars of exchange and, specially, the integrated research project on "Scientific production on higher education in Brazil: 1968-2000" contributed to its advance in terms of the collective reflection it permitted on its role and questions of higher education policy, as well as strengthening its academic production. In a prospective vision and bearing in mind that the work of consolidation of a group like this is an undertaking resulting from a process of permanent construction, the article poses questions to be discussed and debated by its members.

Key-works: Working Group on Higher Education Policy.

Cecília Goulart e Sonia Kramer

Alfabetização, leitura, escrita: 25 anos da ANPEd e 100 anos de Drummond

A partir de revisão realizada com base em diversos textos: históricos, relatórios, livros de programação e de resumos de reuniões anuais da ANPEd, o artigo busca rever a trajetória do grupo de trabalho "Alfabetização, leitura e escrita", no período de 1991 a 2001. Destaca eixos temáticos e áreas de conhecimento trabalhadas, indica e analisa conquistas e fragilidades, mapeando a atuação do GT e revelando aspectos da história da própria Associação. O poeta

Drummond, no ano da comemoração de seus 100 anos, percorreu conosco o período, revelando a realidade estudada para além do visível, ressaltando a simplicidade como critério. $\mathrm{O}$ texto é dedicado à professora Magda Soares, uma das fundadoras do GT, com relevante e marcante produção na área de estudo.

Palavras-chave: alfabetização, leitura e escrita, grupo de trabalho.

Literacy, reading and writing 25 years of ANPEd and 100 years of Drummond

This article seeks to review the trajectory of the working group "Literacy, reading and writing", in the period 1991-2001, based on an analysis of diverse historical texts, reports, programmes and abstracts of the annual meetings of ANPEd. It 